\title{
Endogenous Opioid Blockade and Impulsive Responding in Alcoholics and Healthy Controls
}

\author{
Jennifer M Mitchell', Venessa C Tavares', Howard L Fields ${ }^{1,2,3}$, Mark D'Esposito ${ }^{4}$ and \\ Charlotte A Boettiger*, I,2
}

'Ernest Gallo Clinic and Research Center, University of California at San Francisco, Emeryville, CA, USA; ${ }^{2}$ Department of Neurology, University of California at San Francisco, San Francisco, CA, USA; ${ }^{3}$ Wheeler Center for the Neurobiology of Addiction, University of California at San Francisco, San Francisco, CA, USA; ${ }^{4}$ Helen Wills Neuroscience Institute, University of California at Berkeley, Berkeley, CA, USA

\begin{abstract}
The opioid receptor antagonist naltrexone (NTX) is one of few approved treatments for alcoholism, yet the mechanism by which it reduces drinking remains unclear. In rats, NTX reduces morphine-induced impulsive choice bias; however, nothing is known about the drug's effect on discrete aspects of impulsive behavior in humans, such as decision-making and inhibitory control. Here, we used a modified delay discounting procedure to investigate whether NTX improves decision-making or inhibitory control in humans. We measured the effect of acute NTX (50 mg) on choice between smaller sooner (SS) and larger later monetary rewards and on response errors (motor mismatch) in a high conflict condition in a group of abstinent alcoholics (AA) and healthy control subjects (CS). We previously reported that AA selected the SS option significantly more often than did CS in this paradigm. If the choice bias of AA is due to enhanced endogenous opioid signaling in response to potential reward, NTX should reduce such bias in the AA group. We found that NTX did not reliably reduce impulsive choice in the AA group; however, NTX's effect on choice bias across individuals was robustly predictable. NTX's effect on choice bias was significantly correlated with scores on Rotter's Locus of Control (LOC) scale; increasingly internal LOC scores predicted increasing likelihood of impulsive choices on NTX. In addition, we found that NTX significantly enhanced control of motor responses, particularly within the CS group. These results suggest that endogenous opioids may impair response selection during decision-making under conflict, and that NTX's effects on explicit decision-making are personality-dependent. Determining the biological basis of this dependence could have important implications for effective alcoholism treatment.

Neuropsychopharmacology (2007) 32, 439-449. doi: I0.1038/sj.npp. I30 I226; published online I 8 October 2006
\end{abstract}

Keywords: decision making; ethanol; inhibitory control; locus of control; naltrexone; response conflict

\section{INTRODUCTION}

The opioid antagonist naltrexone (NTX), is one of only three drugs with US Food and Drug Administration (FDA) approval for the treatment of alcoholism, and is also used in the treatment of other addiction and impulse-control disorders. NTX reduces alcohol consumption, craving, and relapse in subjects with a history of alcohol abuse (O’Brien et al, 1996; Anton et al, 1999; Davidson et al, 1999; Hernandez-Avila et al, 2006; see Heidbreder, 2005 for a recent review). Moreover, NTX significantly reduces ethanol consumption in rats (Stromberg et al, 1998) and monkeys (Boyle et al, 1998). However, the mechanism underlying NTX's efficacy in reducing alcohol intake has yet to be

\footnotetext{
*Correspondence: Dr CA Boettiger, Ernest Gallo Clinic and Research Center, University of California at San Francisco, 5858 Horton St, Suite 200, Emeryville, CA 94608, USA, Tel: + I 5109853973 , Fax: + I 510985 3I0I, E-mail: cab@phy.ucsf.edu

Received 20 April 2006; revised 18 July 2006; accepted 5 September 2006

Online publication: I4 September 2006 at http://www.acnp.org/ citations/Npp09|406060257/default.pdf
}

determined. One possibility is that NTX decreases the rewarding effect of alcohol intake (Swift et al, 1994; Volpicelli et al, 1995; Sinclair, 2001). Another possibility is that NTX reduces drinking by generating aversive side effects, such as nausea, when ethanol is consumed (Davidson et al, 1999; de Wit et al, 1999; McCaul et al, 2000; Mitchell et al, 2005a). However, there is also evidence that NTX significantly reduces alcohol craving in alcoholics during abstinence (Monti et al, 1999; Rohsenow et al, 2000; O'Malley et al, 2002), and improves resistance to thoughts, urges, and behaviors associated with drinking (Anton et al, 1999). Thus, it is plausible that NTX acts, in part, via alteration of certain cognitive processes. Clinical and preclinical data converges on the hypothesis that NTX may reduce impulsive responding. This hypothesis is supported by animal studies that have shown NTX to be effective at decreasing impulsive choice bias. For example, in rats, NTX reverses a morphine induced increase in preference for small immediate rewards over larger delayed rewards (Kieres et al, 2004). Moreover, in humans, NTX attenuates a variety of impulse disorders, including pathological gambling (Kim et al, 2001), binge eating in 
bulimics (Marrazzi et al, 1995), compulsive sexual behavior (Raymond et al, 2002), self-injurious behavior (Symons et al, 2004), and kleptomania (Grant, 2005). Taken together, these results suggest that endogenous opioids promote impulsivity, and that NTX improves self-control by blocking endogenous opioid activity. However, despite this wealth of clinical and animal data, to date, no laboratory studies have explicitly investigated the impact of NTX on impulsive responding in human subjects.

To determine the effect of NTX on discrete elements of impulsive choice behavior in humans, we used a modified delay discounting (DD) task. This DD task allows the separate evaluation of both impulsive decision-making and motor impulsivity. We previously demonstrated that abstinent alcoholics (AA) select the smaller, sooner reward option significantly more frequently than control subjects (CS) in this task (Mitchell et al, 2005b), a tendency we have quantified as the 'Impulsive Choice Ratio' (ICR). If this tendency of AA to choose impulsively reflects an enhancement of endogenous opioid signaling in response to rewarding stimuli, then NTX should reduce the impulsive choice bias of the AA group. Using a double-blind placebo-controlled randomized crossover design, we tested whether discounting of delayed rewards was reduced by a single acute dose of NTX $(50 \mathrm{mg})$, and whether this effect differed between groups. We predicted that NTX would specifically reduce impulsive decision-making, but would have no effect on inhibitory control (or motor mismatch (MM)).

\section{METHODS}

\section{Subjects}

AA subjects $(n=9)$ were recruited through flyers posted by local alcoholism recovery organizations and through referral by addiction treatment professionals. CS $(n=9)$ were recruited by flyers posted in the local community. To minimize systematic differences in physiological state between subject groups, we elected not to recruit active alcoholics, as our protocol would have required those subjects to be in a state of acute withdrawal. AA subjects were recruited on the basis of a minimum of 2 weeks of selfreported abstinence from alcohol. Subjects were screened by telephone before participation. All subjects were between 19 and 38 years of age, and were screened for neurological disease, current treatment for other psychological disorders, and addiction to substances other than alcohol. CS were also screened for a history of alcohol abuse. Owing to the high incidence of chronic tobacco use among alcoholics, nicotine addiction was not considered grounds for exclusion for either group. Subjects who met our inclusion criteria in the phone screening were invited to participate in the experiment, which took place in a laboratory setting on the University of California, Berkeley (UCB) campus. Subjects provided written, informed consent, as approved by the UCB Committee for the Protection of Human Subjects. Subjects were compensated approximately $\$ 150$ for their participation. Subjects participated on 2 days, separated by at least $48 \mathrm{~h}$, to allow complete elimination of NTX from the system. The DD task itself lasted approximately $1 \mathrm{~h}$. In addition to the DD task, during session one, subjects also completed a battery of standard questionnaires (see 'Behavioral Inventories').

\section{NTX Administration}

After being screened for contraindications for NTX, including a urine pregnancy test for women, subjects were administered either a $50 \mathrm{mg}$ NTX capsule or an identical placebo capsule. Experimenter and subject were both blind to capsule content; capsule order was counter balanced across subjects. During session one, subjects were asked to fill out a series of questionnaires, and were then free to relax during the remaining time. Administration of the DD task began approximately $3 \mathrm{~h}$ following capsule ingestion. This interval was chosen to minimize any acute physiological effects of NTX during the DD task while still achieving significant opioid receptor antagonism (Atkinson, 1984; Swift et al, 1994; King et al, 1997).

\section{Behavioral Inventories}

We quantified alcohol abuse severity via the AUDIT (Saunders et al, 1993), based on its sensitivity and strong correlation to the DSM-III-R diagnosis for alcoholism (eg, Bradley et al, 1998), and its demonstrated cross-cultural validity (Cherpitel, 1998). Domain I of the Drug Use Screening Inventory (DUSI-I; Tarter, 1990) provided additional information regarding the severity of each subject's alcohol abuse behaviors. DUSI-I scores are reported in terms of the percent of affirmative answers from Domain I, part B. For the AUDIT \& DUSI-I questionnaires only, subjects were instructed to answer based on the year before achieving abstinence if they had ceased consuming alcohol. To determine whether group differences in other affective and/or behavioral factors could impact NTX effects on choice behavior, we also collected responses from each subject for the Beck Depression Inventory (BDI; Beck and Steer, 1987), the Depression Anxiety and Stress Scales (DASS; Lovibond and Lovibond, 1993), the Barratt Impulsivity Scale-11 (BIS; Barratt, 1994), Rotter's Locus of Control Scale (LOC; Rotter, 1966), the South Oaks Gambling Screen (SOGS; Lesieur and Blume, 1987), the Future Time Perspective Inventory (FTPI; Wallace, 1956), and the Schizotypal Personality Questionnaire (SPQ; Raine, 1991). We also collected information about familial alcohol abuse using the Family Tree Questionnaire (FTQ; Mann et al, 1985). Occupation and education information were collected to calculate the Hollingshead Socioeconomic Status (SES) score (Hollingshead, 1975).

\section{DD Task}

The details of this procedure have been reported elsewhere (Mitchell et al, 2005b). In brief, during each session subjects completed eight blocks of 47 or 48 trials, with rest periods between blocks, as needed (total duration $\sim 1 \mathrm{~h}$ ). Subjects were given a brief practice session $(\sim 4 \mathrm{~min})$ before beginning the $\mathrm{DD}$ task. For each trial, two options were presented, each consisting of a dollar amount at a point in time. On every trial, one option was one of six 'full' amounts, ( $\$ 1, \$ 2, \$ 5, \$ 10, \$ 20$, or $\$ 100)$ at one of five future delays ( 1 week, 2 weeks, 1 month, 3 months, or 6 months). 
The other option was a lesser amount available at a sooner point in time. The discount rate randomly varied among the following four percentages: $70,85,90$, or $95 \%$. We refer to these two alternatives as the 'earlier' vs the 'later' option. Right-left position of the earlier and later options was randomized. Subjects indicated their choice by pressing one of two buttons on a keypad. Trial type was indicated by an instruction cue, which indicated how the subject was to select one of the two options that subsequently appeared (see Figure 1). Trials were one of four instruction conditions: WANT (W), DON'T WANT (DW), SOONER, and LARGER, which are considered together as 'CONTROL' (CON). In the $\mathrm{W}$ condition, subjects chose the option they preferred. In the DW condition, subjects were asked to make the same evaluation, but to press the button corresponding to the opposite choice. On CON trials, subjects selected the side with the sooner time point or larger amount of money. This verified that subjects comprehended the task and were compliant with task instructions. Trial types were randomly intermixed, with weighted ratios of $1 / 2$ for the $\mathrm{W}$ condition and $1 / 6$ each for each of the other conditions. The order of trial types did not vary across subjects; however, the delayed amount, delay time, and discount rate were randomly selected on each trial. The decision to use hypothetical rewards was based on results from numerous studies comparing choices for real $v s$ hypothetical monetary rewards in discounting paradigms (Critchfield and Kollins, 2001; Johnson and Bickel (2002); Madden et al, 2003; Madden et al, 2004; Lagorio and Madden, 2005).

\section{Data Analysis}

We used two indices of discounting, the proportion of earlier choices, which we have termed the ICR, and the cumulative gain ratio (CGR). The latter metric is a ratio of the total dollar amount chosen over the course of the experiment, divided by the maximum total dollar amount available. These values were calculated across all $\mathrm{W}$ trials, as well as separated according to delay time and delayed amount. As described previously (Mitchell et al, 2005b), our design does not allow robust determination of a hyperbolic discount rate $(k)$, thus $k$ was not used as a dependent measure. We also calculated the criterion interest rate acceptance threshold for each subject. To do so, we first calculated the simple interest rate for each trial according to the following equation:

$$
\begin{aligned}
\text { Interest Rate }= & (\text { Later amount }- \text { Sooner amount }) \\
& /(\text { Sooner amount } * \text { delay })
\end{aligned}
$$

where delay is equal to the Later time-Sooner time interval. We then plotted the percentage of trials in which the subject accepted the Later option against the interest rate. We fitted the data with a logistic regression of the following form:

$$
y=\mathrm{e}^{(a+b * x)} /\left(1+\mathrm{e}^{(a+b * x)}\right)
$$

Given the two alternative forced-choice structure of our task design, we defined the interest rate criterion acceptance threshold (from the logistic fit) as the interest rate for which the subject chose the Later option $75 \%$ of the time. We were unable to successfully fit a logistic regression curve to the interest rate choice data for one subject, so these data were excluded from further interest rate analyses. Reward preference in DW trials was inferred as the non-selected option. On the basis of these responses, we calculated an inferred ICR (iICR) for each delay time. The absolute difference between the ICR and iICR for each delay time was calculated, and the sum of the |ICR-iICR | across all delay times was used as an index of motor control. We refer to this sum value as ' $M M$ '. a

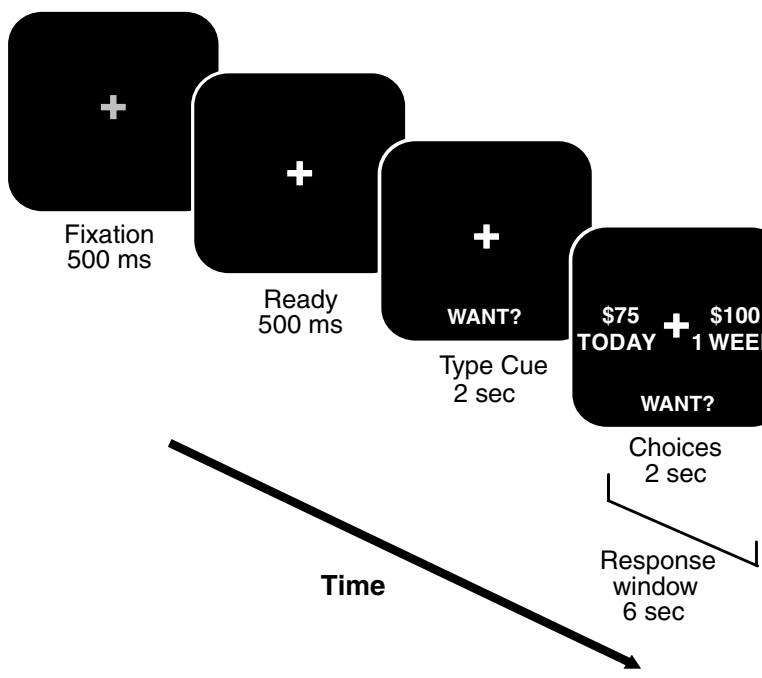

b
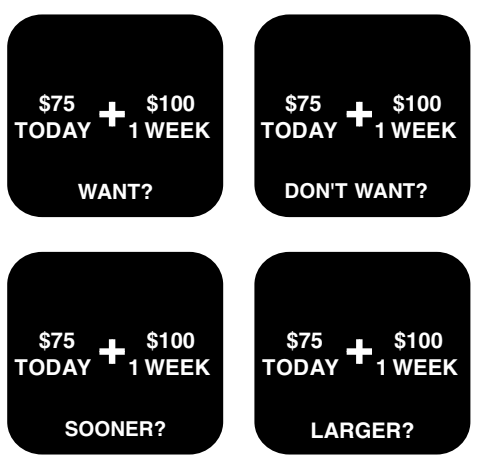

Figure I Illustration of behavioral paradigm. (a) The temporal sequence of events are shown for one example WANT (W) trial. Illumination of a fixation point ('Ready') indicated the initiation of each trial. The instruction cue was then displayed for two seconds, alerting the subject to the upcoming trial type. The two options ('earlier' and 'later') were then presented while the instruction cue remained on the screen. The choices remained on the screen for $2 \mathrm{~s}$,

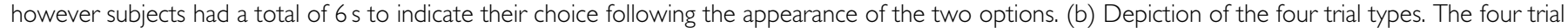
types included W, DW, and two CON: SOONER and LARGER. Trial ratio was I/2 for the W condition and I/6 each for the other three trial types. 
For single factor statistical comparisons between subject groups, we used unpaired two-tailed $t$-tests for continuous measures and $\chi^{2}$ tests for categorical measures. For multifactorial comparisons, we used mixed repeated measures ANOVAs as implemented in SPSS, with group as a between subjects factor. Where sphericity assumptions were violated, a Greenhouse-Geisser non-sphericity correction was applied. Post hoc paired comparisons were performed where indicated using two-tailed $t$-tests. To ensure the validity of parametric statistical tests, when data were not normally distributed, appropriate arcsine-root transformation was applied before making statistical comparison. Simple regression analysis and macro-based analyses of covariance (ANCOVA) were performed using Excel. To estimate which continuous variables had the greatest predictive value for the NTX effects on ICR and MM, linear multiple regression analyses were carried out using SPSS. For each multiple regression analysis, we entered variables stepwise, divided into four blocks. The blocks were as follows: block 1 -group (1 or 2), age, years of education, HH-SES; block 2-AUDIT, DUSI-1B, FTQ density, time abstinent; block 3 -BDI, DASS, SOGS, LOC, FTPI-I-max extension, FTPI-Imean extension, BIS, SPQ; block 4-WANT trial RT change, DW trial RT change, CON trial RT change.

\section{RESULTS}

\section{Demographic and Psychometric Data}

The AA and CS groups differed somewhat in terms of demographic variables. Specifically, on average, the CS had a higher level of education, and were more likely to be Caucasian and female; age and SES did not differ between groups (Table 1). However, we have shown previously that gender, ethnicity, and education level do not have a significant impact on performance in this DD task (Mitchell et al, 2005b), a result we have confirmed in the present study. Consistent with our expectations, the AA subjects reported significantly higher levels of alcohol abuse and alcohol-related problems (Table 1). Members of the AA group also reported a significantly higher incidence of familial alcohol abuse (Table 1). To determine whether any additional individual or group differences in personality traits predicted NTX response, we collected additional psychometric data from subjects. The psychometric data are shown in Table 1 . We found that the AA and CS groups did not differ on measures of emotional distress (DASS) or future orientation (FTPI). However, the AA group scored significantly higher on measures of depression (BDI), impulsivity (BIS-11), and gambling (SOGS). Furthermore, the AA group had a significantly less internal LOC. The impact of these differences on NTX's effects are considered in the multiple regression analyses below.

\section{Task Reaction Times}

Reaction time (RT) data from the DD task are shown in Table 2. A mixed model ANOVA indicated no significant main effect of acute NTX administration $\left(\mathrm{F}_{1,16}=2.35\right.$, $p=0.145)$ or subject group $\left(\mathrm{F}_{1,16}=0.01, p=0.915\right)$ on $\mathrm{RT}$. However, consistent with our previous findings, we did detect a significant effect of trial type $\left(\mathrm{F}_{1.18,18.9}=48.18\right.$,
Table I Demographic and Psychometric Data

CS $(n=9)$ AA $(n=9) t(16)$ p value

\begin{tabular}{lcccl}
\hline General & & & & \\
Age (years) & $28 \pm 6$ & $31 \pm 6$ & 1.14 & NS \\
Education (years) & $19 \pm 4$ & $15 \pm 4$ & 2.22 & 0.041 \\
Hollingshead SES & $52 \pm 9$ & $40 \pm 17$ & 1.82 & NS \\
Gender (\% male subjects) & 50 & 77.8 & & NS* \\
Ethnicity (\% white subjects) & 87.5 & 55.6 & & NS* \\
& & & & \\
Alcohol-related & & & & \\
AUDIT & $6 \pm 2$ & $21 \pm 8$ & 5.20 & $<0.001$ \\
DUSI-I (B) (\%) & $17 \pm 17$ & $71 \pm 29$ & 4.83 & $<0.001$ \\
FTQ density (\%) & $17 \pm 14$ & $49 \pm 21$ & 3.76 & 0.002 \\
& & & & \\
Psychometric & & & & \\
Depression (BDI) & $2.3 \pm 2.2$ & $9.2 \pm 9.1$ & 2.22 & 0.042 \\
Impulsivity (BIS-II) & $58.7 \pm 10.2$ & $74.9 \pm 8.2$ & 3.72 & 0.002 \\
Emotional distress (DASS) & $7.1 \pm 5.9$ & $18.3 \pm 23.8$ & 1.37 & NS \\
Future orientation (FTPI) & $38 \pm 22$ & $22 \pm 17$ & 1.69 & NS \\
Internal-External control (LOC) & $7.0 \pm 2.7$ & $10.2 \pm 3.2$ & 2.31 & 0.034 \\
Gambling (SOGS) & $0 \pm 0$ & $2.1 \pm 2.5$ & 2.51 & 0.023 \\
& & &
\end{tabular}

AA, abstinent alcoholic; CS, control subject; SES, socioeconomic status; AUDIT, Alcohol Use Disorders Identification Test; DUSI-I, Drug Use Screening Inventory, Domain I; FTPI, Future Time Perspective Inventory (Maximum Extension, part I); FTQ, Family Tree Questionnaire; BDI, Beck Depression Inventory; BIS, Barratt Impulsivity Scale-I I; DASS, Depression, Anxiety, and Stress Scale; LOC, Rotter's Locus of Control Scale; SOGS, South Oaks Gambling Screen.

Values are reported as mean $\pm S D$. Reported $p$-values reflect the results of unpaired two-tailed comparison between groups. Exact $p$-values reported unless $p<0.001$.

* $p$-value represents results of $\chi^{2}$ test.

Table 2 Reaction Time Data

\begin{tabular}{lcc}
\hline & PBO & NTX \\
\hline CS $(n=9)$ & & \\
CON & $1320 \pm 347$ & $1399 \pm 306$ \\
W & $1994 \pm 413$ & $2087 \pm 38 \mid$ \\
DW & $2229 \pm 482$ & $2258 \pm 424$ \\
& & \\
AA (n=9) & & $1661 \pm 537$ \\
CON & $1531 \pm 527$ & $1953 \pm 616$ \\
W & $180 \mid \pm 548$ & $2163 \pm 622$ \\
DW & $2045 \pm 55 \mid$ &
\end{tabular}

AA, abstinent alcoholic; CS, control subject; W, WANT trials; DW, DON'T WANT trials; CON, Control trials (SOONER and LARGER).

Reaction times (in $\mathrm{ms}$ ) for each trial type in the delay discounting task following the placebo $(\mathrm{PBO})$ or $50 \mathrm{mg}$ naltrexone (NTX; mean $\pm \mathrm{SD}$ ).

$p<0.001)$. Post hoc paired-comparisons determined that the trial type effect on RTs was due to significantly longer RTs for W trials than for CON trials (1959 vs $1478 \mathrm{~ms}$, respectively, $\left.\mathrm{F}_{1,16}=34.46, p<0.001\right)$, and significantly longer RTs for DW trials than for W trials (2174 vs $1959 \mathrm{~ms}$, 
respectively, $\left.\mathrm{F}_{1,16}=48, p<0.001\right)$. We found no significant interaction between drug and group $\left(\mathrm{F}_{1,16}=0.25, p=0.622\right)$ or drug and trial type $\left(\mathrm{F}_{2,32}=0.77, p=0.47\right)$. Additionally, NTX had no effect on CON trial accuracy $\left(\mathrm{F}_{1,16}=1.16\right.$, $p=0.298)$.

\section{Acute NTX does not Reduce Impulsive Choice in Either Group}

Consistent with previous findings (Vuchinich and Simpson, 1998; Petry, 2001; Mitchell et al, 2005b), the AA group made impulsive choices significantly more often than the CS group $\left(\mathrm{F}_{1,16}=5.846, p=0.028\right)$. Also, consistent with our previous findings (Mitchell et al, 2005b), ICR was sensitive to both the later reward delay (Figure $2 \mathrm{c} ; \mathrm{F}_{1.74,27.83}=12.35$; $p<0.001$ ) and the later reward amount (Figure 2d;
$\left.\mathrm{F}_{1.86,29.67}=17.49, \quad p<0.001\right)$. However, as shown in Figure 2a, NTX did not significantly alter ICR for either subject group $\left(\mathrm{F}_{1,16} 0.60, p=0.451\right)$. We also failed to detect a significant drug $\times$ group interaction $\left(\mathrm{F}_{1,16}=0.02\right.$, $p=0.899)$. We did, however, find a significant drug $\times$ later reward amount $\times$ group interaction $\left(\mathrm{F}_{5,80}=4.51, p=0.001\right.$; see Figure 2d). Post hoc tests determined that this interaction was due to a group difference in the relative effect of NTX on the probability of discounting $\$ 5$ or $\$ 10$ $\left(\mathrm{F}_{1,16}=5.0, p=0.04\right)$. In the AA group, the mean ratio of sooner choices given a $\$ 10$ later reward increased on NTX to a greater extent ( 0.72 to 0.79$)$ than for a later reward of $\$ 5$ (0.82 to 0.84; Figure 2d, left panel). In the CS group, the opposite relationship was true: NTX increased discounting of a $\$ 5$ later reward to a greater degree (0.48 to 0.58$)$ than a $\$ 10$ later reward (0.37 to 0.39; Figure 2d, right panel).
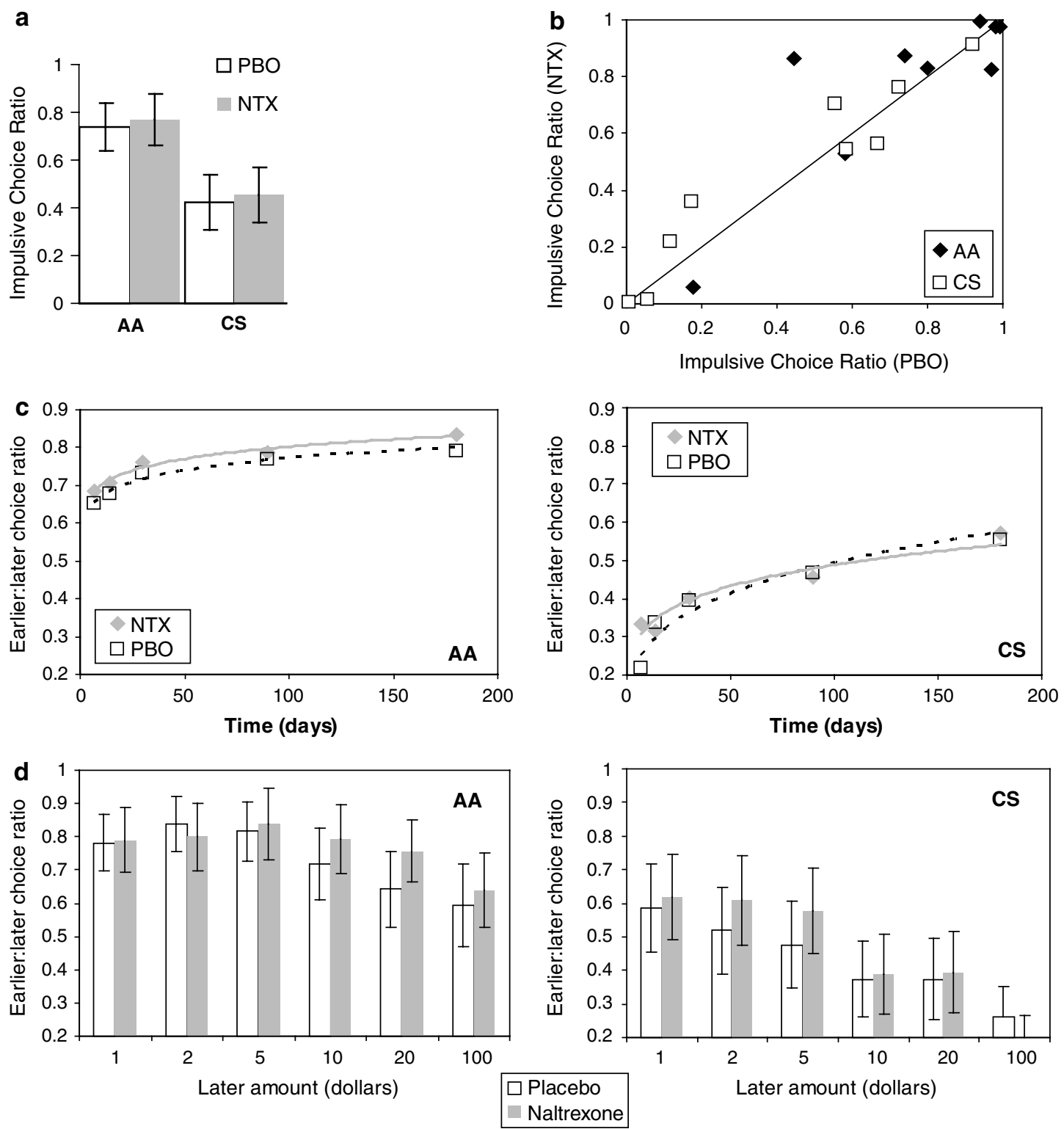

Figure 2 Effect of NTX on impulsive choices in the W condition. (a) Bar plot showing ICR on placebo (PBO) and NTX for each group. (b) Scatterplot of impulsive choices (ICR) for NTX vs placebo, demonstrating inter-subject variability of effect. (c) Effect of NTX on ICR as a function of time. Left panel: AA group, Right panel: CS group. (d) Effect of NTX on ICR as a function of later reward amount. 
In addition to the ICR, we also examined whether NTX affected CGR. We found that NTX failed to alter the total reward amount that subjects accumulated $\left(\mathrm{F}_{1,16}=1.22\right.$, $p=0.285)$. We also found no significant drug $\times$ group interaction for CGR $\left(\mathrm{F}_{1,16}=0.18, p=0.675\right)$. Finally, we tested whether NTX impacted subjects' criterion interest rate acceptance threshold. We found a significant main effect of group on the interest rate criterion threshold $\left(F_{1,15}=6.49, p=0.022\right)$, with the CS group being willing to accept significantly lower interest rates (placebo criterion rates, AA: $24 \pm 7 \%$, CS: $6 \pm 2 \%)$. However, as for the other choice measures (ICR and CGR), we found neither a significant NTX effect $\left(\mathrm{F}_{1,15}=0.73, p=0.406\right)$, nor a significant drug $\times$ group interaction $\left(\mathrm{F}_{1,15}=0.11\right.$, $p=0.748)$. Taken together, these results indicate that NTX does not have a generalized effect on decision-making behavior under normal circumstances in either AA or CS.

\section{Acute NTX Reduces MM in CS, but not AA}

In contrast to the lack of consistent NTX effects on explicit decision-making, we detected a robust NTX effect on MM. NTX reduced the absolute difference between each subject's ICR from the $\mathrm{W}$ condition, and their $i \mathrm{ICR}$ from the DW condition (Figure $3 ; \mathrm{F}_{1,16}=5.77 ; p$ 0.029). A mixed-design repeated measures ANOVA found no main effect of group on $\mathrm{MM}\left(\mathrm{F}_{1,16}=2.05 ; p=0.172\right)$. Although there was a trend towards greater mismatch reduction in the CS group (Figure 3), we found no significant group $\times$ drug interaction

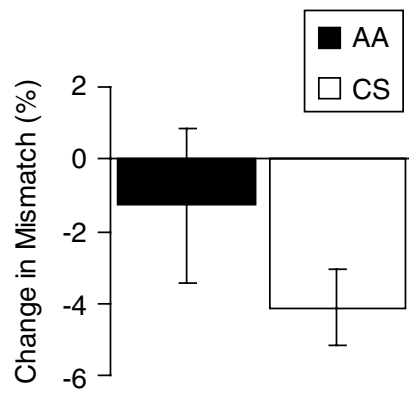

b

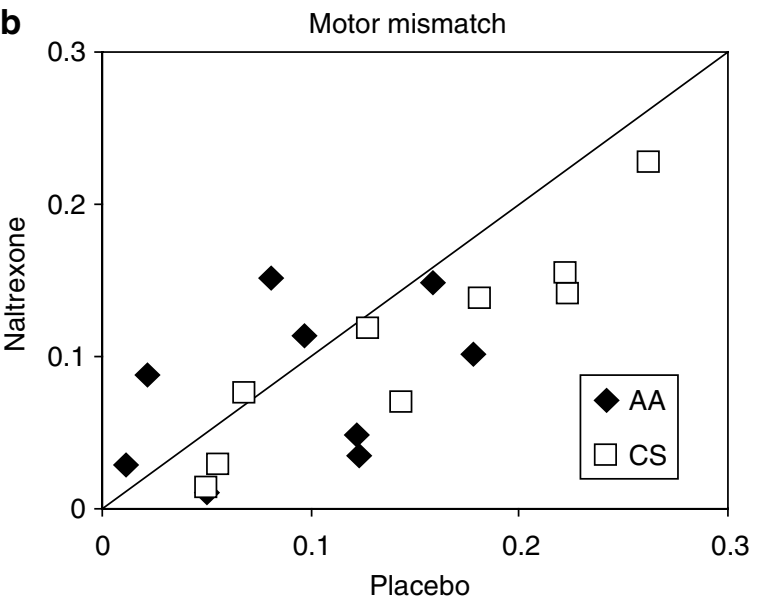

Figure 3 Effect of NTX on inhibitory control. (a) Effect of NTX on mismatch in the DW condition, with the AA and CS groups plotted separately. (b) Scatterplot of mismatch for NTX vs placebo, demonstrating inter-subject variability of effect, and showing more uniformly improved inhibitory control for CS on NTX.
$\left(\mathrm{F}_{1,16}=1.58 ; p=0.228\right)$. As shown in Figure $3 \mathrm{~b}$, within the AA group, we observed considerable inter-subject variability in the effect of NTX on MM $\left(t_{7}=0.54, p=0.645\right)$, whereas the effect of NTX on MM was very consistent in the CS group, as a paired $t$-test demonstrated $\left(t_{7}=4.34\right.$, $p=0.003)$.

\section{Factors Predicting NTX Effect on Impulsive Choice}

We next tested the value of the collected demographic and psychometric measures in predicting the effect of NTX on ICR. We found that only one variable, the LOC score held significant predictive value $\left(r=-0.51, t_{17}=-2.4, p=0.03\right.$; Table 3; Figure 4a). Lower LOC scores, reflecting a more internal attribution style, correlated with a NTX-induced increase in impulsive choice, whereas more external attribution style correlated with reduced impulsive choice on NTX. We found that no other factor added into the model added significantly more predictive power than LOC alone for the NTX effect on ICR. As this correlation appeared to be driven by the AA group, we repeated the multiple linear regression procedure with data from each group independently. Within the AA group, we again found a significant correlation between LOC scores and NTX's effect on ICR $\left(r=-0.80, t_{8}=-3.47, p=0.01\right)$, however, the FTPI (part I) mean event extension time provided significant added predictive power to the LOC alone (Table 3). In contrast, for the CS group, we found that the FTPI part I mean extension score alone demonstrated

Table 3 Multiple Regression Analyses: Factors Predicting NTX Effect on ICR

\begin{tabular}{|c|c|c|c|}
\hline & B & SE B & $\beta$ \\
\hline \multicolumn{4}{|l|}{ Step 1} \\
\hline Constant & 20.96 & 7.92 & \\
\hline LOC & -2.06 & 0.86 & $-0.5 \mid *$ \\
\hline \multicolumn{4}{|l|}{ AA group only } \\
\hline \multicolumn{4}{|l|}{ Step 1} \\
\hline Constant & 46.09 & 12.85 & \\
\hline LOC & -4.18 & 1.21 & $-0.80 *$ \\
\hline \multicolumn{4}{|l|}{ Step 2} \\
\hline Constant & 55.57 & 9.51 & \\
\hline LOC & -3.71 & 0.85 & $-0.7 \mid * *$ \\
\hline FTPI-I mean extension & -1.98 & 0.68 & $-0.47 *$ \\
\hline \multicolumn{4}{|l|}{ CS group only } \\
\hline \multicolumn{4}{|l|}{ Step 1} \\
\hline Constant & -8.67 & 4.78 & \\
\hline FTPI-I mean extension & 1.22 & 0.43 & $0.73 *$ \\
\hline
\end{tabular}

B: beta value; SE B: beta value standard error; $\beta$ : standardized beta; $A \mathrm{~A}$, abstinent alcoholic; CS, control subject; LOC, Rotter's Locus of Control Scale; FTPI, Future Time Perspective Inventory (part I).

Results from Multiple Linear Regression analysis of predictors of NTX effect on ICR.

* $p<0.05, * * * 0.01$ 

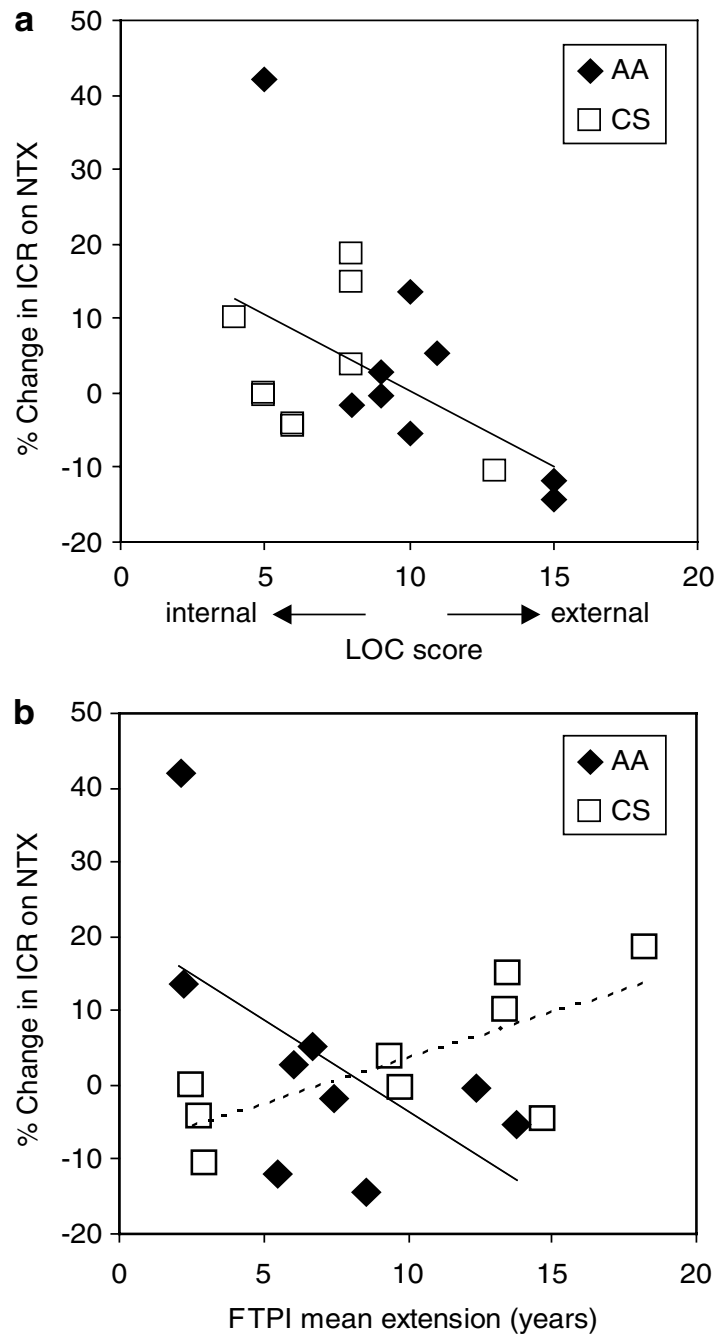

Figure 4 Factors predicting NTX effect on choice behavior. (a) Percent change in ICR vs LOC score. The line reflects a linear fit derived from the data of all subjects considered together, however the AA and CS groups are plotted separately for illustrative purposes. (b) Percent change in ICR vs mean FTPI-part I score. Dashed lines reflect linear fits derived from the data of the CS group, solid lines reflect fit derived from data of the AA group.

significant correlation with the NTX effect on ICR $(r=0.73$, $t_{8}=2.83, p=0.03$; Table 3 ). Importantly, this correlation is in the opposite direction relative to the correlation seen in the AA group, which likely explains why the FTPI mean extension did not emerge as a significant predictive factor in the whole group multiple regression analysis (Figure $4 \mathrm{~b}$ ). Among the CS group, greater future orientation correlated with increased ICR on NTX, whereas among the AA group, greater future orientation was associated with decreased ICR on NTX.

Given the small sample sizes of the present study, it is important to consider whether we have adequate statistical power to rule out correlations between other factors and NTX's effect on ICR. However, power analyses indicated that we had greater statistical power to detect a significant relationship with every other variable, excepting FTQ density, than for LOC. It remains possible that we failed to detect additional, weaker correlations, so negative findings should be considered with some caution.
Table 4 Multiple Regression Analyses: Factors Predicting NTX Effect on MM

\begin{tabular}{lrcc}
\hline & B & SE B & $\boldsymbol{\beta}$ \\
\hline Step I & & & \\
Constant & -3.43 & 1.09 & $-0.48^{*}$ \\
$\Delta$ DWRT & 0.15 & 0.07 & \\
& & & \\
CS group only & & & $-0.67 *$ \\
Step I & 1.14 & 2.33 & \\
Constant & -0.75 & 0.31 & \\
LOC & & & \\
\hline
\end{tabular}

DW, DON'T WANT trials; CS, control subject; RT, reaction time; LOC, Rotter's Locus of Control Scale.

Results from Multiple Linear Regression analysis of predictors of NTX effect on MM. Conventions as for Table 3.

\section{Factors Predicting NTX Effect on MM}

We also used multiple linear regression to identify any demographic or psychometric measures that had significant predictive value in terms of the NTX effect on MM. We found that a single variable had significant predictive power: the NTX effect on RT in the DW condition. The NTX effect on RT in the DW condition was positively correlated with the effect on MM $\left(r=0.48, t_{17}=2.19, p=0.04\right.$; Table 4; Figure 5a). That is, responding more quickly in the DW condition on NTX was associated with less MM on NTX. No other factor added into the model added significantly more predictive power than the DW RT change alone for the NTX effect on MM. Repeating the multiple regression procedure within the AA group, we found that no factor was significantly correlated with the NTX effect on MM, however, we found a trend for a similar correlation between change in MM and change in DW RT $\left(r=0.59, t_{8}=1.93\right.$, $p=0.09)$. Carrying out the multiple regression procedure within the CS group, we found that a single factor significantly correlated with the NTX effect on MM: LOC score. We found that CS with more external attribution styles showed less MM on NTX $\left(r=-0.67, t_{8}=-2.40\right.$, $p<0.05$; Table 4; Figure 5b). A similar correlation was seen with LOC scores and the effect of NTX on inferred ICR $\left(r=-0.88, t_{8}=-4.92, \quad p=0.002\right)$, consistent with the hypothesis that NTX is reducing MM by reducing errors in the DW condition.

\section{DISCUSSION}

\section{NTX Effects on Impulsive Choice}

In testing the effect of acute NTX on decision-making behavior, we found that NTX did not reliably reduce impulsive choice in the AA group as a whole. However, NTX's effect on choice bias across individuals was found to be robustly predictable by a single factor. Scores on Rotter's LOC scale reliably and robustly predicted NTX's effect on choice bias. This relationship was noted across the entire group of subjects tested, but was particularly strong in the group of AA. Owing to the widely reported variability in the 

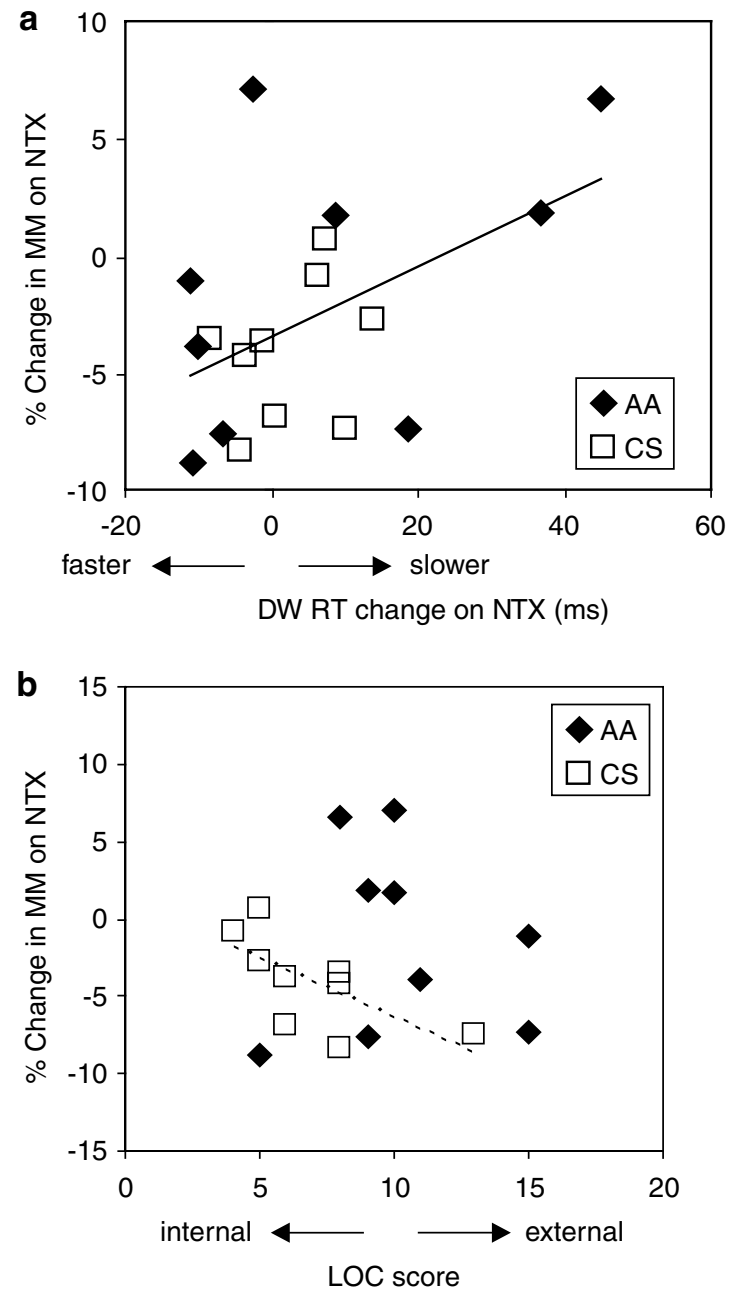

Figure 5 Factors predicting NTX effect on MM. (a) Percent change in $M M$ vs RT change in the DW condition on NTX. Lines reflect linear fits derived from the data of all subjects considered together; AA and CS groups plotted separately for illustrative purposes. (b) Factor correlating with NTX effect on MM in CS. Percent change in MM vs LOC score. The dashed lines reflect linear fit derived from the CS data. Data from the AA group are plotted for illustrative purposes.

therapeutic efficacy of NTX in treating alcoholism (O'Malley et al, 1992, 1996; Volpicelli et al, 1992, 1997; Anton et al, 1999; Chick et al, 2000; Johnson and Ait-Daoud, 2000; Heinala et al, 2001; Krystal et al, 2001; Morris et al, 2001; Guardia et al, 2002), identifying factors that predict therapeutic response to NTX is a critical goal of alcoholism research. Although the cognitive effects of acute and chronic NTX may differ, recent data supports equivalent or greater efficacy of acute NTX dosing, relative to daily maintenance, in reducing excessive alcohol intake (Hernandez-Avila et al, 2006). Thus, determining the cognitive effects of acute NTX doses is warranted. qOur data suggest that LOC scores index a biological difference that impacts NTX's effect on impulsive choice. Strengthening this conclusion is the fact that we have recently replicated the LOC finding in a separate, cohort of 40 subjects (Altamirano et al, 2006). Thus, investigating the predictive value of LOC scores in NTX clinical outcomes is warranted.

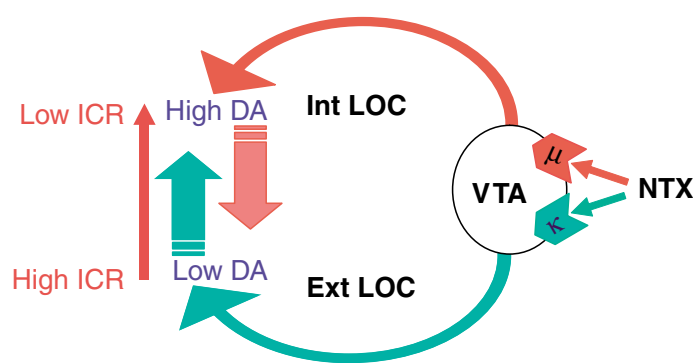

Figure 6 Model depicting opposing actions of NTX (NTX) on ICR. When mu-opioid receptor effects dominate, DA release is reduced and ICR goes up. When kappa-opioid receptor effects dominate, DA release is increased and ICR goes down. Higher baseline DA is predicted by internal (Int) LOC scores, and lower DA levels are predicted by external (Ext) LOC scores.

LOC is a personality trait referring to an individual's perception of control over events and consequences (Rotter, 1966), which has been extensively studied. Much of this work has led to the hypothesis that LOC scores reflect individual differences in tonic frontal dopamine (DA) transmission (Declerck et al, 2006). Evidence includes the correlation of LOC scores with serum DA metabolite levels (De Brabander and deClerck, 2004), as well as with frontal lobe function (Amrhein et al, 1999; Stevens et al, 1999). By this theory, NTX's effect on impulsive choice in this study depended on frontal dopaminergic tone, with low DA subjects becoming less impulsive and high DA subjects more impulsive.

Given that impulsive choice is reduced by acute elevation of DA levels; (de Wit et al, 2002; Wade et al, 2000), a simple explanation of our findings is that NTX exerts frontal DA tone-dependent effects on tonic DA release. This is consistent with studies demonstrating opioid regulation of DA neurons (eg, Ostrowski et al, 1982; Sesack and Pickel, 1992; Oswald and Wand, 2004; Berthele et al, 2005), including those projecting to prefrontal cortex (Margolis et al, 2006). Given that NTX acts at both $\mu$ - and $\kappa$-opioid receptors, which exert opposing effects on forebrain DA release (Spanagel et al, 1992; Herz and Spangel, 1995; Margolis et al, 2006), differential effects of NTX on DA levels could be due to differences in relative $\mu$ - and $\kappa$-mediated effects of NTX, as depicted in Figure 6. Relative $\mu$-receptor to $\kappa$-receptor blockade effects would be expected to differ in subjects with low circulating levels of endogenous $\mu$-receptor ligands, as is the case with alcoholics and their offspring (Govoni et al, 1983; Vescovi et al, 1992; del Arbol et al, 1995; Dai et al, 2005), or in subjects with low levels of $\mu$-receptor expression, as is found in subjects with low frontal DA levels (Berthele et al, 2005) owing to their catechol-O-methyltransferase genotype (Meyer-Lindenberg et al, 2005), and in subjects with the A118G polymorphism of the $\mu$-receptor (Zhang et al, 2005). This latter polymorphism has also shown a functional differentiation in the therapeutic response to NTX (Oslin et al, 2003), and has distinguished alcoholics from non-alcoholics in some populations (Bart et al, 2005). Based on this line of reasoning, we would expect to find a group difference in NTX on decision-making, however given the small sample size and large variance within groups, this study lacked sufficient statistical power to draw such a conclusion. 


\section{NTX Effects on MM}

With respect to the effects of NTX on MM, our data is consistent with one of two possibilities. The first possibility is that NTX improves inhibitory motor control by altering a pathway with differential baseline functioning between the CS and AA groups. A candidate pathway is baseline $\mu$-receptor signaling. As noted above, low $\mu$-receptor ligand tone has been demonstrated in AA. However, an alternative explanation for the increased NTX effect in the CS group is that endogenous opioids are elevated due to more recent alcohol intake rather than a constitutive difference. To our knowledge, however, there is no evidence to date supporting the idea that NTX improves motor control.

A second possibility is that NTX reduces MM by reducing response conflict. This possibility can also explain the differential effects seen in the AA and CS groups. In the CS group, attraction to the larger reward creates response conflict in the DW condition. There, the subjects must override the pull of responding to the more attractive large reward to respond to the small reward. On placebo, CS chose the large reward in DW trials more often than was predicted by their $\mathrm{W}$ condition choices, indicating response errors in the DW condition, as confirmed by postexperiment debriefing. In the CS group, NTX significantly reduced such errors. This result is consistent with NTX reducing response conflict by reducing attentional bias toward desirable stimuli or the tendency to select a preferred reward. In fact, NTX selectively reduces consumption of preferred palatable liquids in rats (Taha $e t$ al, 2006). In contrast, the DW error rate of the AA group was much smaller. This difference in errors could be explained by the fact that for the AA group, the correct response in the DW condition is more often the larger reward. Thus, for AA subjects, attentional bias toward the larger reward reduces, rather than increases, response conflict in the DW condition, resulting in fewer errors (ie, less MM). NTX would then be predicted to have little or no effect on MM in the AA group (or perhaps to slightly increase MM by reducing bias toward the larger reward), which is consistent with our results. If NTX is indeed reducing response conflict owing to choosing against the larger reward, one would predict that RT on placebo in the $\mathrm{W}$ condition would positively correlate with NTX's effect on ICR, which is indeed the case $(r=0.48, t=2.17, p<0.05)$. In other words, if slower RTs in the $\mathrm{W}$ condition indicate greater response conflict owing to attentional bias toward the large reward, and if opioids contribute to such bias, NTX should reduce it. Our results are consistent with this interpretation of NTX's effect.

Finally, the fact that speeding of RT in the DW condition on NTX correlated with the magnitude of MM reduction lends further support to the notion that NTX is reducing response conflict. Although a strictly motor effect of NTX is possible, the alternative that NTX decreases attentional bias toward desirable rewards holds greater appeal, as it is consistent with the results of a number of related studies. For example, NTX selectively reduces consumption of preferred foods (Apfelbaum and Mandenoff, 1981). Moreover, decreased attentional bias toward attractive stimuli by NTX is consistent with data showing that NTX reduces cue-elicited alcohol craving in alcoholics (Monti et al, 1999;
Rohsenow et al, 2000; O'Malley et al, 2002). Thus, effects on attentional bias could be one means by which NTX exerts its therapeutic effects in alcoholics. As previous work has correlated attentional bias toward alcohol-related cues with alcohol abuse severity (Weinstein and Cox, 2006), further exploration of this possibility is needed.

\section{Relevance to Alcoholism}

An important consideration is the relevance of our findings to the ability of NTX to reduce alcohol consumption. As outlined in the Introduction, several possible mechanisms for this effect of NTX on a complex behavior have been proposed, to which we now add the potential shift in preference from immediate to delayed rewards. Our model raises the possibility that NTX reduces impulsive choice in proportion to the degree of $\kappa$-receptor mediated effect relative to $\mu$-receptor mediated effect. This notion is supported by data showing that people with the A118G $\mu$-receptor polymorphism show reduced $\mu$-receptor expression (Zhang et al, 2005), and more effective NTX-mediated abstinence from alcohol (Oslin et al, 2003). However, our small sample sizes make it difficult to conclusively attribute the impulsive choice differences we find between the AA and CS groups to propensity to alcoholism per se, or other related factors, such as depression.

\section{Summary}

In conclusion, we find that the effect of an acute NTX dose on impulsive choice in humans is predicted by the individual's LOC score. We find that a lower LOC, reflecting a more internal attribution style, correlates with an increase in impulsive choice on NTX, whereas a more external attribution style correlates with reduced impulsive choice on NTX. This relationship was particularly strong in the AA group. Future orientation, as measured by the FTPI was also predictive of NTX's effect on impulsive choice, although the direction of the correlation differed between groups. We also found that NTX reduced motor errors in a conflict condition. Our results suggest that this effect was due to a reduction of response conflict, a hypothesis that bears further investigation. Together, the results reported here provide new insights into possible mechanisms for NTX's ability to reduce drinking, and suggest several novel lines of research in this area.

\section{ACKNOWLEDGEMENTS}

We thank G Hjelmstad, S Nicola and M Silver for helpful suggestions. This work was supported by DOD center Grant \#W81XWH-04-1-0154 (CAB and HLF), the Wheeler Center for the Neurobiology of Addiction (JMM), and the Henry $\mathrm{H}$ Wheeler Jr Brain Imaging Center.

\section{REFERENCES}

Altamirano LJ, Kelley EA, Fields HL, D’Esposito M, Boettiger CA (2006). Opioid regulation of impulsive responding under the influence of alcohol. Poster presented at the Society for Neuroscience Annual Meeting. Atlanta, GA, October 14-18, 2006. 
Amrhein PC, Bond JK, Hamilton DA (1999). Locus of control and the age difference in free recall from episodic memory. J Gen Psychol 126: 149-164.

Anton RF, Moak DH, Waid LR, Latham PK, Malcolm RJ, Dias JK (1999). Naltrexone and cognitive behavioral therapy for the treatment of outpatient alcoholics: results of a placebocontrolled trial. Am J Psychiat 156: 1758-1764.

Apfelbaum M, Mandenoff A (1981). Naltrexone suppresses hyperphagia induced in the rat by a highly palatable diet. Pharmacol Biochem Behav 15: 89-91.

Atkinson RL (1984). Endocrine and metabolic effects of opiate antagonists. J Clin Psychiatry 45: 20-24.

Barratt ES (1994). Impulsiveness and aggression. In: Monahan J, Steadman HJ (eds). Violence and mental disorder: Developments in risk assessment The John D and Catherine T MacArthur Foundation series on mental health and development. University of Chicago Press: Chicago. pp 61-79.

Bart G, Kreek MJ, Ott J, LaForge KS, Proudnikov D, Pollack L et al (2005). Increased attributable risk related to a functional muopioid-receptor gene polymorphism in association with alcohol dependence in central Sweden. Neuropsychopharmacology 30: 417-422.

Beck AT, Steer RA (1987). Manual for the Revised Beck Depression Inventory. Psychological Corp: San Antonio, TX.

Berthele A, Platzer S, Jochim B, Boecker H, Buettner A, Conrad B et al (2005). COMT Val108/158Met genotype affects the muopioid receptor system in the human brain: evidence from ligand-binding, G-protein activation and preproenkephalin mRNA expression. NeuroImage 28: 185-193.

Boyle AE, Stewart RB, Macenski MJ, Spiga R, Johnson BA, Meisch RA (1998). Effects of acute and chronic doses of naltrexone on ethanol self-administration in rhesus monkeys. Alcohol Clin Exp Res 22: 359-366.

Bradley KA, Bush KR, McDonell MB, Malone T, Fihn SD (1998). Screening for problem drinking: comparison of CAGE and AUDIT. Ambulatory Care Quality Improvement Project (ACQUIP). Alcohol Use Disorders Identification Test. J Gen Intern Med 13: 379-388.

Cherpitel CJ (1998). Differences in performance of screening instruments for problem drinking among blacks, whites and Hispanics in an emergency room population. J Study Alcohol 59: 420-426.

Chick J, Anton R, Checinski K, Croop R, Drummond C, Farmer $\mathrm{R}$ et al (2000). A multicentre, randomized, doubleblind, placebo-controlled trial of naltrexone in the treatment of alcohol dependence or abuse. Alcohol Alcohol 35: 587-593.

Critchfield TS, Kollins SH (2001). Temporal discounting: basic research and the analysis of socially important behavior. J Appl Behav Anal 34: 101-122.

Dai X, Thavundayil J, Gianoulakis C (2005). Differences in the peripheral levels of beta-endorphin in response to alcohol and stress as a function of alcohol dependence and family history of alcoholism. Alcohol Clin Exp Res 29: 1965-1975.

Davidson D, Palfai T, Bird C, Swift R (1999). Effects of naltrexone on alcohol self-administration in heavy drinkers. Alcohol Clin Exp Res 23: 195-203.

De Brabander B, Declerck CH (2004). A possible role of central dopamine metabolism associated with individual differences in locus of control. Pers Individ Dif 37: 735-750.

de Wit H, Enggasser JL, Richards JB (2002). Acute administration of $d$-amphetamine decreases impulsivity in healthy volunteers. Neuropsychopharmacology 27: 813-825.

de Wit H, Svenson J, York A (1999). Non-specific effect of naltrexone on ethanol consumption in social drinkers. Psychopharmacology (Berlin) 146: 33-41.

del Arbol JL, Aguirre JC, Raya J, Rico J, Ruiz-Requena ME, Miranda MT (1995). Plasma concentrations of beta-endorphin, adrenocorticotropic hormone, and cortisol in drinking and abstinent chronic alcoholics. Alcohol 12: 525-529.

Declerck CH, Boone C, De Brabander B (2006). On feeling in control: a biological theory for individual differences in control perception. Brain Cognition, advance online publication, 27 June 2006; doi:10.1016/j.bandc.2006.04.004.

Govoni S, Bosio A, Di Monda E, Fazzari G, Spano PF, Trabucchi M (1983). Immunoreactive met-enkephalin plasma concentrations in chronic alcoholics and in children born from alcoholic mothers. Life Sci 33: 1581-1586.

Grant JE (2005). Outcome study of kleptomania patients treated with naltrexone: a chart review. Clin Neuropharmacol 28: 11-14.

Guardia J, Caso C, Arias F, Guai A, Sanahuja J, Ramirez M et al (2002). A double-blind, placebo-controlled study of naltrexone in the treatment of alcohol-dependence disorder: results from a multicenter clinical trial. Alcohol Clin Exp Res 26: 1381-1387.

Heinala P, Alho H, Kiianmaa K, Lonnqvist J, Kuoppasalmi K, Sinclair JD (2001). Targeted use of naltrexone without prior detoxification: a factorial double-blind, placebo-controlled trial. J Clin Psychopharmacol 21: 287-292.

Heidbreder C (2005). Recent advances in the pharmacotherapeutic management of drug dependence and addiction. Curr Psychiatry Rev 1: 45-67.

Hernandez-Avila CA, Song C, Kuo L, Tennen H, Armeli S, Kranzler HR (2006). Targeted versus daily naltrexone: secondary analysis of effects on average daily drinking. Alcohol Clin Exp Res 30: 860-865.

Herz A, Spangel R (1995). Endogenous opioids and addiction. In: Tseng LF (ed). The Pharmacology of Opioids. Harwood: Germany. pp 445-462.

Hollingshead A (1975). Hollingshead's Four Factor Index of Social Status. Yale University Press: New Haven, CT.

Johnson BA, Ait-Daoud N (2000). Neuropharmacological treatments for alcoholism: scientific basis and clinical findings. Psychopharmacology 149: 327-344.

Johnson MW, Bickel WK (2002). Within-subject comparison of real and hypothetical money rewards in delay discounting. J Exp Anal Behav 77: 129-146.

Kieres AK, Hausknecht KA, Farrar AM, Acheson A, de Wit $\mathrm{H}$, Richards JB (2004). Effects of morphine and naltrexone on impulsive decision making in rats. Psychopharmacology 173: 167-174.

Kim SW, Grant JE, Adson DE, Shin YC (2001). Double-blind naltrexone and placebo comparison study in the treatment of pathological gambling. Biol Psychiatry 49: 914-921.

King AC, Volpicelli JR, Frazer A, O'Brien CP (1997). Effect of naltrexone on subjective alcohol response in subjects at high and low risk for future alcohol dependence. Psychopharmacology 129: $15-22$.

Krystal JH, Cramer JA, Krol WF, Kirk GF, Rosenheck RA (2001). Naltrexone in the treatment of alcohol dependence. $N$ Engl J Med 345: 1734-1744.

Lagorio CH, Madden GJ (2005). Delay discounting of real and hypothetical rewards III: steady-state assessments, forced-choice trials, and all real rewards. Behav Processes 69: 173-187.

Lesieur HR, Blume SB (1987). The South Oaks Gambling Screen (SOGS): a new instrument for the identification of pathological gamblers. Am J Psychiatry 144: 1184-1188.

Lovibond SH, Lovibond PF (1993). Manual for the Depression Anxiety Stress Scales (DASS). Psychology Foundation Monograph: New South Wales, Australia.

Madden GJ, Begotka AM, Raiff BR, Kastern LL (2003). Delay discounting of real and hypothetical rewards. Exp Clin Psychopharmacol 11: 139-145.

Madden GJ, Raiff BR, Lagorio CH, Begotka AM, Mueller AM, Hehli DJ et al (2004). Delay discounting of potentially real and hypothetical rewards: II. Between- and within-subject comparisons. Exp Clin Psychopharmacol 12: 251-261. 
Mann RE, Sobell LC, Sobell MB, Pavan D (1985). Reliability of a family tree questionnaire for assessing family history of alcohol problems. Drug Alcohol Depend 15: 61-67.

Margolis EB, Lock H, Chefer VI, Shippenberg TS, Hjelmstad GO, Fields HL (2006). $\kappa$ Opioids selectively control dopaminergic neurons projecting to the prefrontal cortex. Proc Natl Acad Sci 103: $2938-2942$.

Marrazzi MA, Markham KM, Kinzie J, Luby ED (1995). Binge eating disorder: response to naltrexone. Int J Obes Relat Metab Disord 19: 143-145.

McCaul ME, Wand GS, Eissenberg T, Rohde CA, Cheskin LJ (2000). Naltrexone alters subjective and psychomotor responses to alcohol in heavy drinking subjects. Neuropsychopharmcology 22: 480-492.

Meyer-Lindenberg A, Kohn PD, Kolachana B, Kippenhan S, McInerney-Leo A, Nussbaum R et al (2005). Midbrain dopamine and prefrontal function in humans: interaction and modulation by COMT genotype. Nat Neurosci 8: 594-596.

Mitchell JM, Bergren LJ, Chen KS, Fields HL (2005a). Prior ethanol consumption predicts aversion elicited by the opioid antagonist naltrexone in rats. Poster presented at the Society for Neuroscience Annual Meeting. Washington, DC, 12-16 November 2005.

Mitchell JM, Fields HL, D'Esposito M, Boettiger CA (2005b). Impulsive responding in alcoholics. Alcohol Clin Exp Res 29: 2158-2169.

Monti PM, Rohsenow DJ, Hutchison KE, Swift RM, Mueller TI, Colby SM et al (1999). Naltrexone's effect on cue-elicited craving among alcoholics in treatment. Alcohol Clin Exp Res 23: 13861394.

Morris PLP, Hopwood M, Whalen G, Gardiner J, Drummond E (2001). Naltrexone for alcohol dependence: a randomized controlled trial. Addiction 96: 1565-1573.

O’Brien CP, Volpicelli LA, Volpicelli JR (1996). Naltrexone in the treatment of alcoholism: a clinical review. Alcohol 13: 35-39.

O'Malley SS, Jaffe AJ, Chang G, Rode S, Schottenfeld RS, Meyer RE et al (1996). Six-month follow-up of naltrexone and psychotherapy for alcohol dependence. Arch Gen Psychiatry 53: 217-224.

O'Malley SS, Jaffe AJ, Chang G, Schottenfeld RS, Meyer RE, Rounsaville B (1992). Naltrexone and coping skills therapy for alcohol dependence. Arch Gen Psychiatry 49: 881-887.

O’Malley SS, Krishnan-Sarin S, Farren C, Sinha R, Kreek MJ (2002). Naltrexone decreases craving and alcohol self-administration in alcohol-dependent subjects and activates the hypothalamopituitary-adrenocortical axis. Psychopharmacology (Berlin) 160: 19-29.

Oslin DW, Berrettini WH, Kranzler H, Pettinati H, Gelernter J, Volpicelli JR et al (2003). A functional polymorphism of the mu-opioid receptor gene is associated with naltrexone response in alcohol dependent patients. Neuropsychopharmacology 28: 1546-1552.

Ostrowski NL, Hatfield CB, Caggiula AR (1982). The effects of low doses of morphine on the activity of dopamine-containing cells and on behavior. Life Sci 31: 2347-2350.

Oswald LM, Wand GS (2004). Opioids and alcoholism. Physiol Behav 81: 339-358.

Petry NM (2001). Delay discounting of money and alcohol in actively using alcoholics, currently abstinent alcoholics, and controls. Psychopharmacology (Berlin) 154: 243-250.

Raine A (1991). The SPQ: a scale for the assessment of schizotypal personality based on DSM-III-R criteria. Schizophr Bull 17: 555-564.

Raymond NC, Grant JE, Kim SW, Coleman E (2002). Treatment of compulsive sexual behaviour with naltrexone and serotonin reuptake inhibitors: two case studies. Int Clin Psychopharmacol 17: 201-205.
Rohsenow DJ, Monti PM, Hutchison KE, Swift RM, Colby SM, Kaplan GB (2000). Naltrexone's effects on reactivity to alcohol cues among alcoholic men. J Abnorm Psychol 109: 738-742.

Rotter JB (1966). Generalized expectancies for internal versus external control of reinforcement. Psychol Monogr 80: 1-28.

Saunders JB, Aasland OG, Babor TF, de le Fuente JR, Grant M (1993). Development of the alcohol use disorders identification test (AUDIT). WHO collaborative project on early detection of persons with harmful alcohol consumption-II. Addiction 88: 791-804.

Sesack SR, Pickel VM (1992). Dual ultrastructural localization of enkephalin and tyrosine hydroxylase immunoreactivity in the rat ventral tegmental area: multiple substrates for opiatedopamine interactions. J Neurosci 12: 1335-1350.

Sinclair JD (2001). Evidence about the use of naltrexone and for different ways of using it in the treatment of alcoholism. Alcohol Alcohol 36: 2-10.

Spanagel R, Herz A, Shippenberg T. (1992). Opposing tonically active endogenous opioid systems modulate the mesolimbic dopaminergic pathway. Proc Natl Acad Sci USA 89: 2046-2050.

Stevens FC, Kaplan CD, Ponds RW, Diederiks JP, Jolles J (1999). How ageing and social factors affect memory. Age Ageing 28: 379-384.

Stromberg MF, Casale M, Volpicelli L, Volpicelli JR, O’Brien CP (1998). A comparison of the effects of the opioid antagonists naltrexone, naltrindole, and beta-funaltrexamine on ethanol consumption in the rat. Alcohol 15: 281-289.

Swift RM, Whelihan W, Kuznetsov O, Buongiorno G, Hsuing H (1994). Naltrexone-induced alterations in ethanol intoxication. Am J Psychiatry 151: 1463-1467.

Symons FJ, Thompson A, Rodriguez MC (2004). Self-injurious behavior and the efficacy of naltrexone treatment: a quantitative synthesis. Ment Retard Dev Disabil Res Rev 10: 193-200.

Taha SA, Norsted E, Lee LS, Lang PD, Lee BS, Woolley JD et al (2006). Endogenous opioids encode relative taste preference. Eur J Neurosci 24: 1220-1226.

Tarter R (1990). Evaluation and treatment of adolescent substance abuse: A decision tree method. Am J Drug Alcohol Abuse 16: $1-46$.

Vescovi PP, Coiro V, Volpi R, Giannini A, Passeri M (1992). Plasma beta-endorphin, but not met-enkephalin levels are abnormal in chronic alcoholics. Alcohol 27: 471-475.

Volpicelli JR, Alterman AI, Hiyashida M, O’Brien CP (1992). Naltrexone in the treatment of alcohol dependence. Arch Gen Psychiatry 49: 876-880.

Volpicelli JR, Rhines KC, Rhines JS, Volpicelli LA, Alterman AI, O'Brien CP (1997). Naltrexone and alcohol dependence: role of subject compliance. Arch Gen Psychiatry 54: 737-742.

Volpicelli JR, Watson NT, King AC, Sherman CE, O'Brien CP (1995). Effect of naltrexone on alcohol 'high' in alcoholics. Am J Psychiatry 152: 613-615.

Vuchinich RE, Simpson CA (1998). Hyperbolic temporal discounting in social drinkers and problem drinkers. Exp Clin Psychopharmacol 6: 292-305.

Wade TR, de Wit H, Richards JB (2000). Effects of dopaminergic drugs on delayed reward as a measure of impulsive behavior in rats. Psychopharmacology 150: 90-101.

Wallace M (1956). Future time perspective in schizophrenia. J Abnorm Psychol 52: 240-245.

Weinstein A, Cox WM (2006). Cognitive processing of drug-related stimuli: the role of memory and addiction. J Psychopharmacol, advance online publication, 9 January 2006; doi:10.1177/ 0269881106061116

Zhang Y, Wang D, Johnson AD, Papp AC, Sadee W (2005). Allelic expression imbalance of human mu opioid receptor (OPRM1) caused by variant A118G. J Biol Chem 280: 32618-32624. 